\title{
Investigating the relationship between model organic compounds and ultrafiltration membrane fouling
}

\author{
Boksoon Kwon ${ }^{\mathrm{a}}$, H.K. Shon ${ }^{\mathrm{b}}$, Jaeweon Cho ${ }^{\mathrm{c} *}$ \\ ${ }^{a}$ Environmental Analysis Center, The Environmental Technology Institute, Woongiin Coway Co., Ltd., Korea \\ ${ }^{b}$ Faculty of Engineering, University of Technology, P.O. Box 123, Sydney, Broadway, NSW 2007, Australia \\ ${ }^{c}$ NOM Ecology National Research Laboratory, Department of Environmental Science and Engineering, Gwangju Institute of Science and \\ Technology (GIST), 1 Oryong-dong, Buk-gu, Gwangju 500-712, Korea \\ Tel.+82 (62) 970-2443; Fax +82 (62)970-2434; email:kbs523@coway.co.kr, jwcho@gist.ac.kr, hkshon@eng.uts.edu.au, jwcho@gist.ac.kr
}

Received 28 January 2008; accepted 3 July 2009

\begin{abstract}
A B S T R A C T
The aims of this study were to investigate the fouling mechanisms of model organic compounds (MOCs) on two ultrafiltration membranes [composite regenerated cellulose (YM100) and polyethersulfone (PES)] and the relationship between fouling and membrane characteristics, flux decline, and the streaming potential (SP). Two alginic acids (polymer and dimmer, AA), abietic acid (AbA), colominic acid (CA), and $N$-acetylneuraminic acid (NA) were selected as MOCs to test their membrane fouling potential through flux decline and SP. The fouling caused by the two AAs, which contained many polysaccharides, was the highest among MOCs, but this fouling was external (solute deposition on the membrane surface) and reversible as polysaccharides did not strongly adsorb onto the YM100 and PES membranes. CA also caused external fouling of the two membranes; however, AbA caused internal (solute adsorption on the pores wall of membrane) and irreversible fouling of the PES membrane. NA, which contained amino sugars, exhibited very low fouling of both membranes. The hydrophilic YM100 membrane experienced less fouling than the hydrophobic PES membrane with all MOCs. The measurement of the SP using a modified dead-end filtration cell was employed to evaluate the flux decline due to MOCs.
\end{abstract}

Keywords: Fouling; Organic matter; Mechanism; Streaming potential; Ultrafiltration

\section{Introduction}

Membrane fouling due to natural organic matter (NOM) has been a major challenge in the operation membrane processes [1-4]. Some NOM materials may cause external fouling, the deposition of solutes on the membrane surface; while, others may cause internal fouling, the adsorption on the pore walls, with both forms of fouling being either reversible or irreversible. Such internal and/or external foulings are affected by

${ }^{*}$ Corresponding author the solute size, chemical properties, and the interaction between the solute and membrane. Many researchers have suggested that humic substances are the most serious foulants, causing irreversible fouling through membrane adsorption and pore plugging [5-7]. Jermann et al. [7] found that qualitatively severe irreversible fouling was caused by membrane adsorption of foulant; this fouling was more prominent for humic acid as compared to polysaccharides (alginate) using a polyethersulfone (PES) membrane. Nevertheless, other studies showed that hydrophilic, non-humic, dissolved or colloidal NOM might be a more significant 
foulant for UF membranes, namely polysaccharides and proteins [8,9]. Cho et al. [1] indicated; via analysis of Fourier transform infrared (FTIR) spectra of fouled membranes, that polysaccharide components in NOM were the major foulant. Moreover, Kimura et al. [8] reported that polysaccharides foul the membrane by pore blockage and gel layer formation and that the irreversible fouling was mainly caused by neutral polysaccharide fraction.

However, analyses of foulants are insufficient for the identification of major fouling substances as NOM is structurally complex, with various components and uncertain reactivity. Studying the effect of individual model component in NOM is needed for identifying the main fouling compound. Selecting model organic compounds (MOCs) that are essential contaminants of natural water sources is believed to be a difficult process, and many compounds can be selected, of these:

- Alginic acid (AA) is a biopolymer (linear polymer polysaccharide of $\beta$-(1 $\rightarrow 4)$-D-mannuronic acid and $\alpha-(1 \rightarrow 4)$-L-guluronic acid) susceptible to degradation, abundant in the cell walls of brown algae, and has a potential importance in natural water contamination [10].

- Abietic acid (AbA) is a major component of the rosin fraction of oleoresin, synthesized by grand fir (Abies grandis (Douglas ex D. Don) Lind.), lodgepole pine (Pinus contorta Douglas ex Louden) and many other conifer species. It is a constituent of the major class of environmental toxic compounds, with potential health hazards to animals, humans, and plant life [11].

- $N$-Acetylneuraminic acid (NA) is widely distributed as a structural component of mucopolysaccharides, glycoproteins, and glycolipids in several kinds of animal cell; while in the case of microorganisms, it is well known as a component of colominic acid, which exists in capsules of certain types of Escherichia coli [12].

- Colominic acid (CA) is a mixture of poly( $N$-acetylneuraminic acid) homologues, with different degrees of polymerization [13], produced from bacterial broth.

NOM fouling was reported to be directly associated to flux decline in ultrafiltration (UF) membrane filtration systems $[7,14,15]$. Zhu and Nyström [15] also reported a high flux loss due to fouling by protein for both hydrophobic and hydrophilic UF membranes. Flux decline was investigated by Weis et al. [16] who concluded that flux decline was related to membrane roughness and controlled by the membrane surface morphology, hydrophobicity, and surface charge. The surface charge of synthetic membranes can significantly influence separation properties and fouling tendency $[17,18]$. The electro-kinetics in membranes play an important role in the transport of solute across a membrane. The interaction between an electrolyte solution and a charged membrane forms an electrical double layer. The widely used practical and convenient technique to measure the membrane surface charge is the streaming potential (SP) [19-23].

The SP is generated across the flow path of an electrolyte solution and membrane surface when hydraulic pressure is applied [22]. It can be measured by two different methods, i.e., flow through the pores of a membrane [19-22,24] or across the membrane surface [23, 25]. Pontié et al. [22] discussed the variation of SP across different UF membranes at fixed ionic strength but with variable pressure (0-1.8 bar) and concluded that variations of $\Delta \phi$ (electrical potential difference) versus $\Delta P$ (transmembrane pressure) are linear with a negative slope ( $\phi$ decreases when $P$ increases). In another study, Pontié et al. [24] reported that negatively charged species adsorbed on the membrane increase the surface charge density of the membrane and therefore the SP decreases. They added that the membrane appears to be more negative as adsorption of the NOM present in the feed occurs. In the same way, Jermann et al. [7] observed that more negative SPs of membrane are reached when fouled with either humic acid or alginate. Consequently, the SP analysis presents information which illustrates the importance of the surface charge of the membrane on fouling mechanisms [26].

In order to identify the role of different fouling materials, the fouling mechanisms of those materials in a membrane filtration system should be simultaneously investigated. The objectives of this study were to investigate the fouling of various MOCs which are likely to be present in natural waters, in association with different UF membrane types (hydrophilic versus hydrophobic). The relationship between fouling and membrane characteristics, flux decline and the SP was also investigated.

\section{Experimental}

\subsection{MOCs and solution preparation}

Five different MOCs were used in this study to identify their role in the fouling phenomena on two UF membranes. The MOCs, supplied by SigmaAldrich, were two commercial AAs with different molecular weights $240 \mathrm{~kg} / \mathrm{mol}$ (polymer AA, Fig. 1a) and $352 \mathrm{~g} / \mathrm{mol}$ (dimmer AA, Fig. 1b), AbA $\left(\mathrm{C}_{20} \mathrm{H}_{30} \mathrm{O}_{2}, 302.5 \mathrm{~g} / \mathrm{mol}, \mathrm{X} \log P=4.4\right.$, Fig. $\left.1 \mathrm{c}\right), \mathrm{NA}$ 
<smiles>CCCO[C@H]1[C@@H](C(=O)O)O[C@@H](O[C@@H]2[C@@H](C(=O)O)O[C@H](CC)[C@@H](O)[C@H]2O)[C@H](O)[C@@H]1O</smiles>

(a) AA from brown algae (Polymer)<smiles>CC(C)C1=CC2=CCC3C(CCC[C@@]3(C)C(=O)O)[C@@]2(C)CC1</smiles><smiles>[X]OC(=O)[C@H]1O[C@H](O)[C@@H](O)[C@H](O)[C@@H]1O[C@H]1O[C@H](C(=O)O)[C@@H](O)[C@H](O)[C@H]1O</smiles>

(b) AA potassium salt (Dimmer)<smiles>CC(=O)N[C@H]1[C@@H](O)C[C@](O)(C(=O)O)O[C@H]1C(O)CO</smiles>

(c) $\mathrm{AbA}$

(d) NA

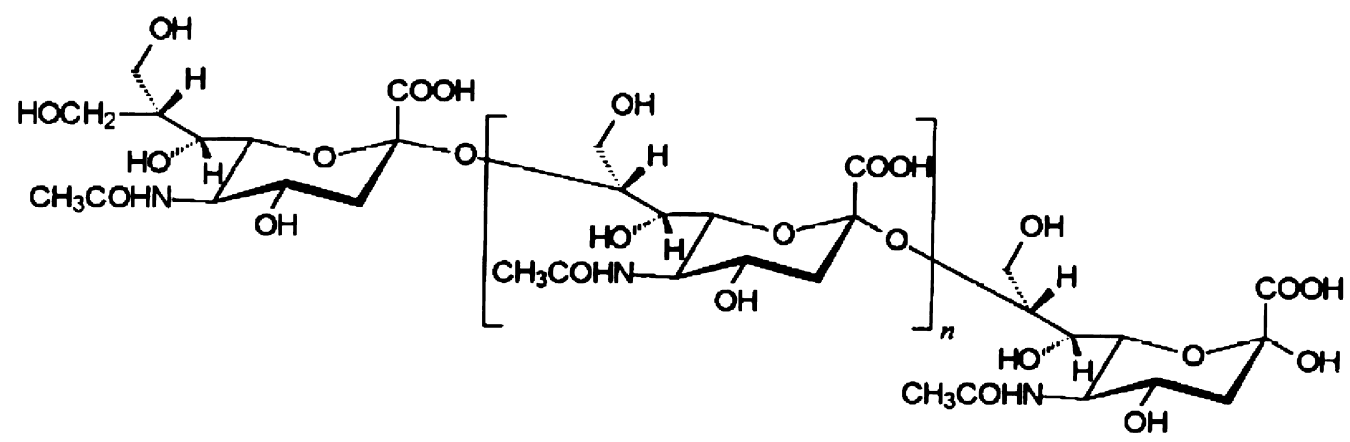

(f) $\mathrm{CA}$

Fig. 1. Chemical structure of MOCs: alginic acid (AA), abietic acid (AbA), N-acetylneuraminic acid (NA), and colominic acid (CA).

$\left(\mathrm{C}_{11} \mathrm{H}_{19} \mathrm{NO}_{9}, 309.3 \mathrm{~g} / \mathrm{mol}, \mathrm{X} \log P=-3.7\right.$, Fig. $\left.1 \mathrm{~d}\right)$ and CA (30 kg/mol, Fig. 1e). All MOCs were dissolved in MQ water and filtered with $0.45 \mu \mathrm{m}$ microfilter, The dissolved organic carbon (DOC) concentration of these solutions was adjusted to approximately $5 \mathrm{mg} / \mathrm{L}$ measured by a TOC analyzer (TOC-5000A, Shimadzu, Japan). For AA, an alkali solution at pH 11 was used to dissolve the AA. Then, the $\mathrm{pH}$ of the solution was adjusted to $\mathrm{pH} 7$.

\subsection{UF membranes}

The UF membranes tested were YM100 and PES (Millipore Corporation) (Fig. 2). According to the manufacturer, the YM100 membrane is suitable for high recovery, with a relatively hydrophilic tight microstructure and low adsorption; while the PES membrane is for high flow, with an open microstructure. The properties of the membranes are shown in Table 1. 


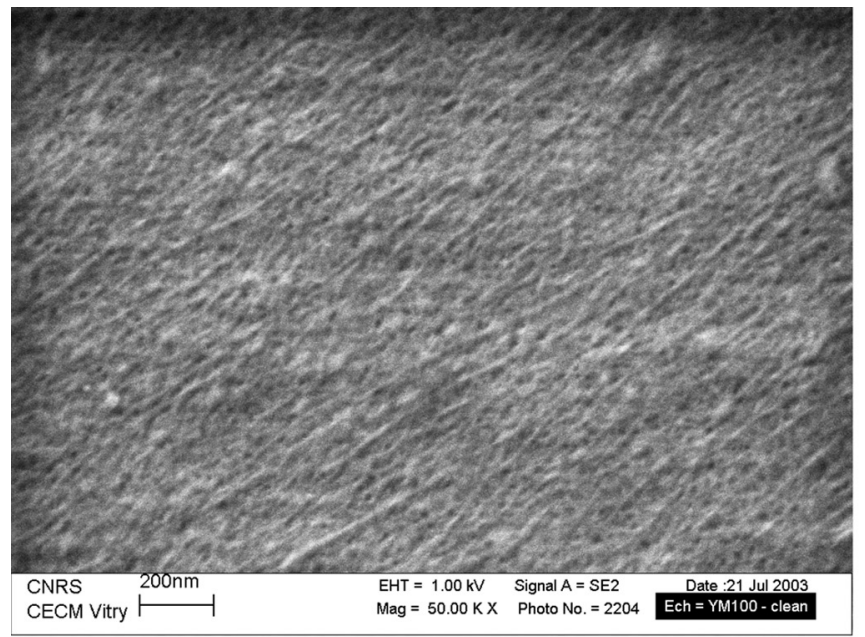

(a) YM100 membrane

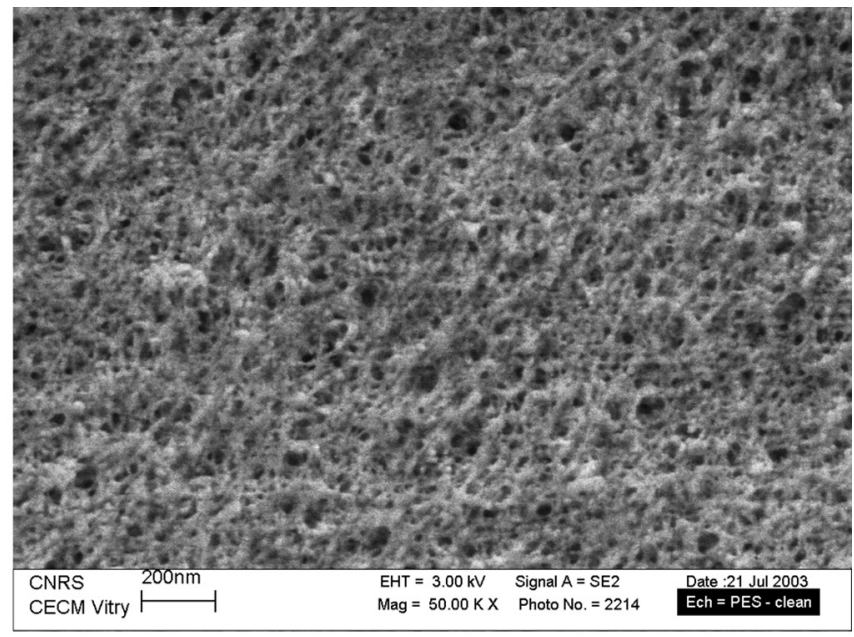

(b) PES membrane

Fig. 2. FESEM (field emission scanning electro microscopy) of (a) clean YM100 and (b) PES membranes.

\subsection{Fouling and hydraulic cleaning experiment}

Fouling experiments were conducted using a stirred UF cell ( $400 \mathrm{~mL}$ volume, Amicon $\mathbb{R}$ and Millipore Corporation, Model 8400). A scheme layout of the setup used is shown in Fig. 3.

All membranes used in these experiments were cleaned with MQ (deionized and sterilized water produced from the Milli-Q water system (Millipore Corporation)) to remove humectants on the membrane prior to the filtration tests. The MQ water containing the humectants derived from the membranes was replaced several times with fresh MQ water, with the membranes then stored in a refrigerator until being used. The feed solution (i.e., MOC solution) was adjusted to $\mathrm{pH} 7$ using $0.1 \mathrm{~N} \mathrm{NaOH}$ or $0.1 \mathrm{~N} \mathrm{HCl}$, at a temperature of $23 \pm 1^{\circ} \mathrm{C}$, and fed into the membrane cell from a vessel (capacity 5 $\mathrm{L}$, feed reservoir) pressurized by nitrogen gas at 0.3 and 0.5 bar for the PES and YM100 membranes, respectively. This difference in pressure was applied because the two membranes had different permeabilities, which was compensated by nitrogen gas pressure regulation applied on the feed solution to have similar experimental conditions for both membranes. A detailed description of the methodology used is shown in Fig. 4.

During filtration, the mass of the MOC was transferred to the membrane by pressure. After the flux decline test with stirring of the MOC feed solution at $200 \mathrm{rpm}$, the entire MOC solution in the UF cell was removed and then MQ water was filled into the cell. The solution in the $5 \mathrm{~L}$ reservoir was also replaced with $\mathrm{MQ}$ water. MQ water filtration of the fouled membrane was conducted to compare the flux with the flux decline generated from the MOC feed solution. This difference was used to explain the hydraulic resistance of the adsorbed layer formed by the MOC filtration. Some deposited or adsorbed MOCs may be detached from the membrane surface by physical washing, such as hydraulic cleaning (normal backwash) with stirring the cell at $400 \mathrm{rpm}$ without applying any pressure, which led to flux recovery. After this cleaning step, MQ filtration was repeated to observe the flux recovery. The same fouling experiments were repeated using each MOC.

Table 1

Characteristics of the YM100 and PES membranes

\begin{tabular}{llllll}
\hline Membrane & MWCO $^{\mathrm{a}}(\mathrm{kDa})$ & Material & Polarity & $\begin{array}{l}\text { Permeability } \\
\left(\mathrm{L} / \mathrm{m}^{2} / \mathrm{h} \text { bar }\right)\end{array}$ & $\begin{array}{l}\text { Intrinsic membrane } \\
\text { resistance }(1 / \mathrm{m})\end{array}$ \\
\hline YM100 & 100 & Regenerated cellulose & Hydrophilic & $860( \pm 27)$ & $6.08 \mathrm{E} \pm 11( \pm 1.91 \mathrm{E}+10)$ \\
PES & 100 & Polyethersulfone & Hydrophobic & $1520( \pm 40)$ & $3.44 \mathrm{E} \pm 11( \pm 9.25 \mathrm{E}+09)$ \\
\hline
\end{tabular}

${ }^{\text {a }}$ Molecular weight cut off.

${ }^{\mathrm{b}}$ Pure water permeability (values are means \pm standard deviation).

${ }^{c}-R_{\mathrm{m}}=\Delta P / \eta_{\mathrm{T}} J_{\mathrm{V}}\left(R_{\mathrm{m}}\right.$, intrinsic membrane resistance $\left(\mathrm{m}^{-1}\right) ; \eta_{\mathrm{T}}$, feed water viscosity at ambient temperature $T,\left(\mathrm{Ns} / \mathrm{m}^{2}\right) ;$ and $J_{\mathrm{v}}$, flux of the permeate water $\left.(\mathrm{m} / \mathrm{s})\right)$. 


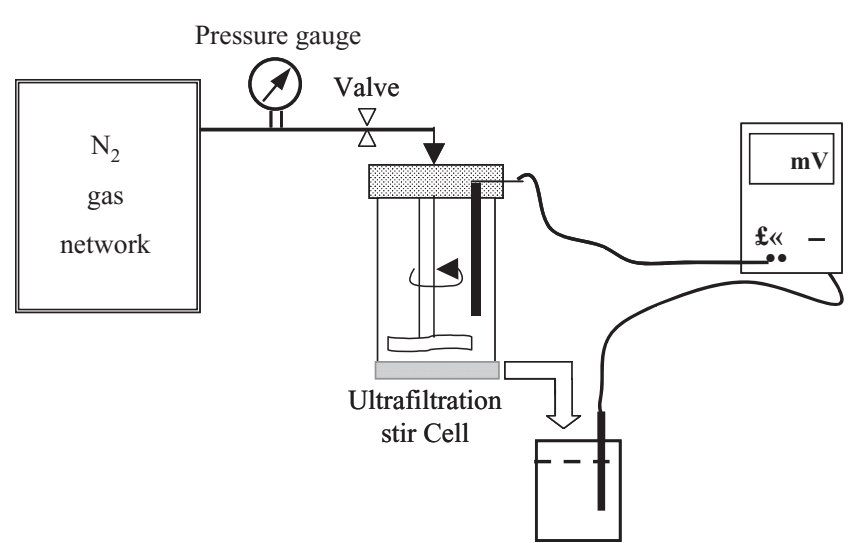

Fig. 3. The scheme of UF membrane filtration system.

\subsection{SP measurements}

The experimental apparatus (Fig. 3) for the SP measurements used in this study was incorporated with the use of a UF membrane cell $(50 \mathrm{~mL}$ volume, Amicon $(\mathbb{R})$ and Millipore Corporation, Model 8050). The concentration of electrolyte solution was $10^{-3} \mathrm{M} \mathrm{KCl}$. A pair of electrodes $(\mathrm{Ag} / \mathrm{AgCl})$ was used to measure the potential difference across the membrane. Upon altering the applied pressure, the potential difference $(\Delta \phi)$ between feed in the cell (with $200 \mathrm{rpm}$ stirring) and permeate solution was recorded using a high sensitivity impedance voltmeter. The SP value $(\nu=\Delta \phi / \Delta P)$ was defined as the potential difference $\triangle \phi=\phi_{\mathrm{f}}-\phi_{\mathrm{p}}$ (, f: feed, p: permeate) per unit of applied pressure $(\Delta P)$. The SP measurement was used to obtain information about the electro-kinetics interactions between the MOCs and the membranes. The SP

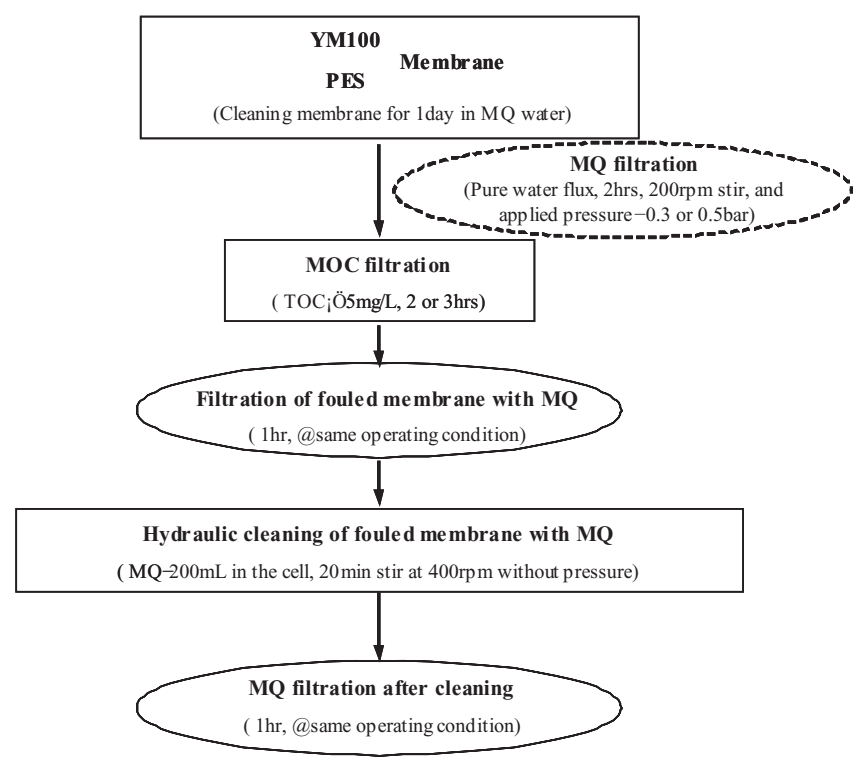

Fig. 4. Layout of membrane filtration experimental procedure. measurements of the clean YM100 and PES membranes were conducted by plotting the potential difference with increasing pressure (from 0 to 1.2 bars). The slope of potential difference $(\triangle \Phi)$ versus pressure $(\Delta P)$ curve was defined as the SP coefficient $(\nu)$.

\subsection{Pyrolysis-gas chromatography/mass spectrometry (GC/MS)}

The specific composition of each MOC was investigated to identify the chemical interaction between MOCs and the membranes. Pyrolysis-GC/MS was used to find the major thermal decomposition products present in the MOCs. Approximately 350-450 $\mu \mathrm{g}$ of the MOCs (as powder) were filled into the middle portion of a $100 \mu \mathrm{L}$ quartz tube, with both sides blocked by quartz wool (CDS Analytical, Inc.). The sample tube was injected into the pyrolysis interface (CDS 1500, valve interface), placed into a platinum filament of the pyrolysis probe (Pyroprobe2000, Chemical data systems, Oxford, PA). The oven was equipped with a Fisons GC8000 split/splitless injection interfaced with a MD 800 quadrupole mass spectrometer. Flash pyrolysis was performed in the platinum filament heated to a final temperature of $625^{\circ} \mathrm{C}$ at a rate of $20^{\circ} \mathrm{C} / \mathrm{ms}$, where it was maintained for $20 \mathrm{~s}$. After the flash pyrolysis, the thermal degradation fragments were separated by GC. The oven with a 30-meter DB-Wax (J\&W Scientific) fused-silica capillary column was temperatureprogrammed from 30 to $220^{\circ} \mathrm{C}$ at a rate of $3{ }^{\circ} \mathrm{C} / \mathrm{min}$. The fragments were then identified by a mass spectrometer, operated at $70 \mathrm{eV}$, and scanned from 20 to $450 \mathrm{amu}$ at $1 \mathrm{scan} / \mathrm{s}$.

\section{Results}

\subsection{Pyrolysis-GC/MS results of MOCs}

The predominant fragments in the pyrochromatograms of AAs, polymer AA, and dimmer AA, were 2-furancarboxaldehyde (furfural), 2-propanone, and 1-hydroxy (hydroxypropanone) (Table 2). The polymer AA has a tighter and more complex configuration, thus, it is more difficult to be measured via pyrolysis than the monomer AA. Both AAs were mainly comprised polysaccharides fragments. Polymer AA provided some fragments containing carboxylic acids, but the dimmer AA did not contain any carboxylic acids. Consequently, their transports into the membrane may differ because of this structural dissimilarity as well as their molecular weight difference. 
Table 2

Pyrochromatograph profile of MOCs (alginic acid (AA), abietic acid (AbA), $N$-acetylneuraminic acid (NA), and colominic acid (CA)). Compounds for each MOC are listed in order of retention time and separated by semicolon

\begin{tabular}{|c|c|}
\hline MOCs & Pyrochromatograph profile \\
\hline A (polymer) & $\begin{array}{l}\mathrm{CO}_{2} ; \text { acetaldehyde; 1,3-cyclopentadiene; furan; acetone; furan,2-methyl; 2-butanone; benzene; 2,3 } \\
\text { butanedione; toluene; 2-propanone,1-hydroxy-; 2-cyclopenten-1-one; acetic acid; 2-furancarboxaldehyde } \\
\text { formic acid; propanoic acid; 2-hydroxycyclopent-2-en-1-one; uracil; phenol; 2-furancarboxylic acid }\end{array}$ \\
\hline AA (dimer) & $\begin{array}{l}\mathrm{CO}_{2} \text {; acetaldehyde; acetone; 2-butanone; benzene; 2,3-butanedione; toluene; ethylbenzene; p-xylen; benzene, } \\
\text { 1,2-dimethyl-; cyclopentanone; cyclopentanone, 2-methyl; 2-butanone, 3-hydroxy-; 2-propanone,1-hydroxy-; } \\
\text { 2-cyclopenten-1-one; 2-cyclopenten-1-one, 2-methyl-; acetic acid; 2-propanone, 1-[acetyloxy]-; 3-furaldehyde; } \\
\text { 2-cyclopenten-1-one,3-methyl-; 2,3-dimethylcyclopent-2-en-1-one; 3-ethylcyclopent-2-en-1-one; 2-cyclopent- } \\
\text { 1-one, 2-hydroxy-3-methyl-; phenol, 2-methyl-; phenol; phenol 2,5-dimethyl-; phenol, 3-methyl- }\end{array}$ \\
\hline $\mathrm{AbA}$ & $\begin{array}{l}\mathrm{CO}_{2} ; \text { 2-butadiene, 2-methyl-; 1,3-cyclopentadiene; acetone; 1,3-cyclopentadiene, 5-methyl; 1,3-dimethyl-1- } \\
\text { cyclohexene; benzene; toluene; cyclopentadiene, 3-ethylidene-1-methyl-; ethylbenzene; p-xylene; benzene, } \\
\text { [1-methylethyl]-; benzene, 1,3-dimethyl-; benzene, 1-ethyl-2-methyl-; styrene; benzene, 1-methyl-3-[methy- } \\
\text { lethyl]-; benzene, 1-ethenyl-3-methyl-; propanoic acid; O-isopropenyltoluene; benzene, methyl[1-methylethe- } \\
\text { nyl]-; acetic acid; 1H-indene, 2,3-dihydro-1,3-dimethyl-; indene; propanoic acid; propanoic acid, 2-methyl-; } \\
\text { benzene, [1-methyl-2cyclopropen-1-yl]-;2-propanoic acid, 2-methyl-; naphtalene; naphtalene, 1-methyl-; naphta- } \\
\text { lene, 2-[1-methylethyl]; naphthalene, 2,6-dimethyl-; naphthalene, 2-[1-methylethyl]-; naphthalene, 2-ethenyl-; } \\
\text { naphthalene, 1-methyl-7-[1-methylethyl]-; acenaphthylene }\end{array}$ \\
\hline NA & $\begin{array}{l}\mathrm{CO}_{2} \text {; acetaldehyde; acetone; 2-propenal; furan,2-methyl; 2-butanone; acetonitrile; pyridine; pyridine, 2-methyl- } \\
\text {; 2-propanone, 1-hydroxy-; acetic acid; pyrrole; acetamide; ethanone, 1-[1H-pyrrol-2-yl-]- }\end{array}$ \\
\hline CA & $\begin{array}{l}\mathrm{CO}_{2} \text {; acetaldehyde; 1,3-cyclopentadiene; acetone; 1,3-cyclopentadiene, methyl-; 2-butanone; ethanol; benzene; } \\
\text { acetonitrile; toluene; pyridine; cyclopentanone; 2-cyclopenten-1-one, 2-methyl-; acetic acid; pyrrole; } \\
\text { 2-cyclopenten-1-one, 3-methyl-; 1H-pyrrole, 3-methyl-; acetamide; ethanone, 1-[1H-pyrrol-2yl]-; phenol; } \\
\text { phenol, 3-methyl- }\end{array}$ \\
\hline
\end{tabular}

The pyrochromatogram of the AbA exhibited many different compounds, as compared to other acids: various different types of benzene and naphthalene fragments for polyhydroxyaromatic biopolymers and an acid component (propanoic acid).

The pyrolysis fragments of the NA and CA indicated that these acids were derived from bacterial cells, as they provided specific fragments, such as the acetamide from amino-sugars and present in the bacterial cell walls. The pyrolysis fragments of these acids have also been observed in the colloid fraction of NOM. The NA included many different biopolymer types of compounds, such as protein (pyrrole), amino sugars (acetonitrile and acetamide), and polysaccharides (hydroxypropanone and acetic acid). The main difference in chemical profiles between CA and NA was the abundance of acetic acid in the CA and acetamide in the NA (Table 2).

\subsection{UF membrane - hydrophobicity, MOCs molecular weight, and flux decline}

Fouling experiments were conducted with MOCs using both the YM100 (relatively hydrophilic) and PES (relatively hydrophobic) membranes at $\mathrm{pH} 7$ (Figs. 5-8). According to the flux decline tests, peculiar flux trends were observed with different solutions and membranes. All the flux decline graphs (Figs. 5-8) were divided into three regions i.e., flux decline of MOC, MQ filtration with fouled membrane, and MQ filtration after normal backwash.

Flux decline was more severe for the dimmer AA than for the polymer AA, regardless of membrane type. Membrane polarity (hydrophobic versus hydrophilic) was not correlated to flux decline (Fig. 5) and flux reduction was similar for both YM100 and PES membranes. YM100 membrane (Fig. 5a) fouled with AA (polymer) experienced flux reduction of $260 \mathrm{~L} / \mathrm{m}^{2} / \mathrm{h}$, while a flux reduction of $300 \mathrm{~L} / \mathrm{m}^{2} / \mathrm{h}$ was recorded for the fouling caused by AA (dimmer).

In the same way, flux decline trends of the PES membrane fouled with AA (polymer) and AA (dimmer) was similar to those observed with the YM100 membrane (both Fig. 5a and b). The formation of AA adsorbed layer on the membrane surface caused hydraulic resistance and resulted in flux losses. However, the adsorbed AA layer did not hinder the solvent (i.e., MQ) flux through both membranes (Fig. 5a and b), as compared to the initial fluxes.

Table 3 provides the DOC values of feed, permeate, and retentate. After normal backwash, the recovered (i.e., after fouling followed by the washing) and the 


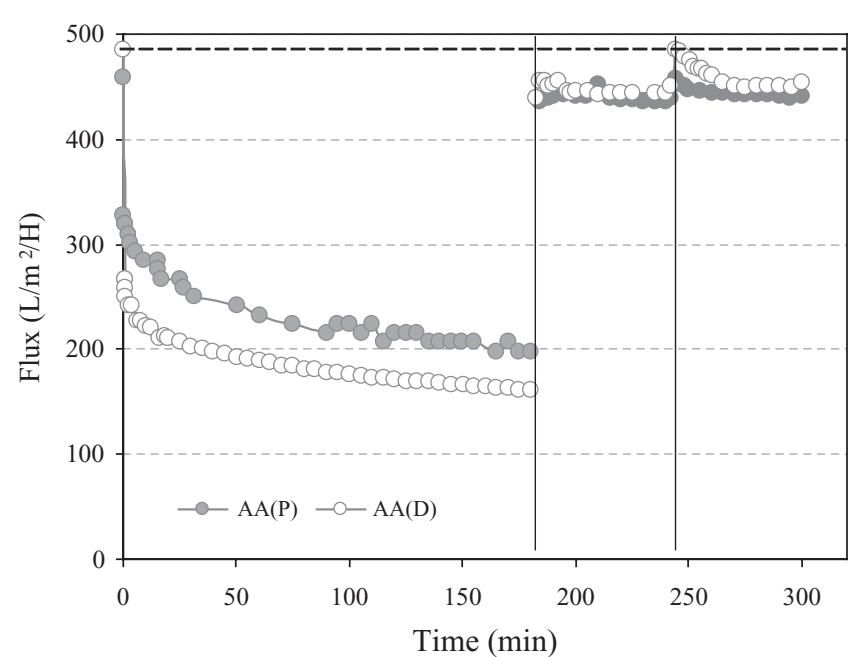

(a) AA with YM100

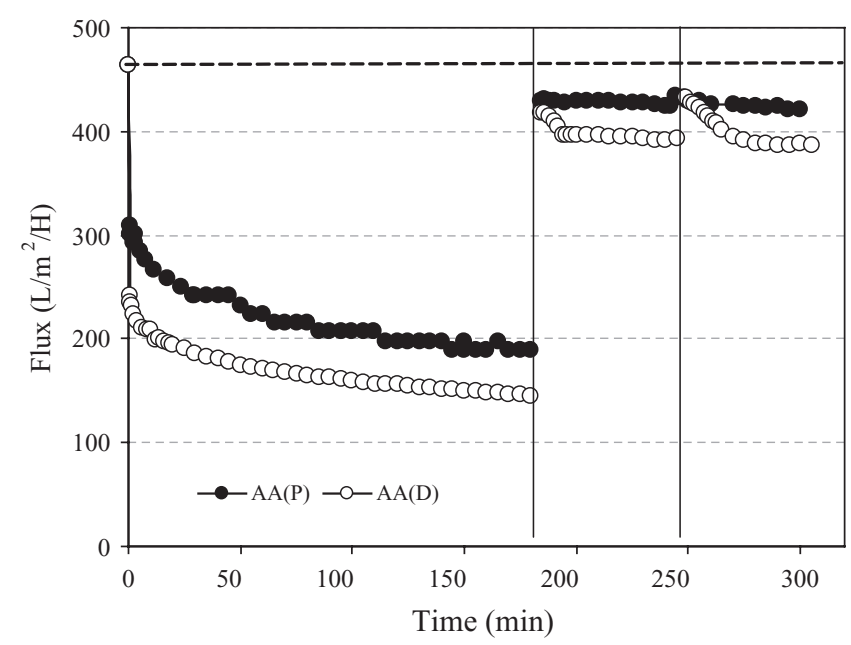

(b) AA with PES

Fig. 5. Flux decline caused by alginic acid (AA) filtration (0-180 min), MQ water filtration with fouled membrane (180-245 $\mathrm{min}$ ), and MQ water filtration after normal backwash (245-300 min) using the (a) YM100 and (b) PES membranes.

initial fluxes were similar. This indicates that the fouling with the AAs was reversible and external regardless of membrane characteristics (the membrane surface) as the DOC values of the solution retained in the cell (approximately $400 \mathrm{~mL}$ ) were relatively high (Table 3); whereas, that of the permeate were relatively low. According to these results, all the AA compounds seemed to be retained by the membrane, regardless of any molecular weight difference. Therefore, of all the possible fouling requisites (e.g., concentration polarization, pore blocking, adsorption, and gel layer formation), the fouling in this case seemed to be mainly caused by concentration polarization.

When using AbA, the YM100 membrane (Fig. 6a) experienced flux reduction of $50 \mathrm{~L} / \mathrm{m}^{2} / \mathrm{h}$, while a higher flux decline of $190 \mathrm{~L} / \mathrm{m}^{2} / \mathrm{h}$ was recorded for the PES membrane (Fig. 6b). After normal backwash, the PES membrane experienced irreversible membrane fouling in opposition to the YM100 membrane for which flux restoration was possible.

CA fouled membranes showed higher flux decline than when fouled with NA (Fig. 7a and b). The significant flux decline was more pronounced in the PES

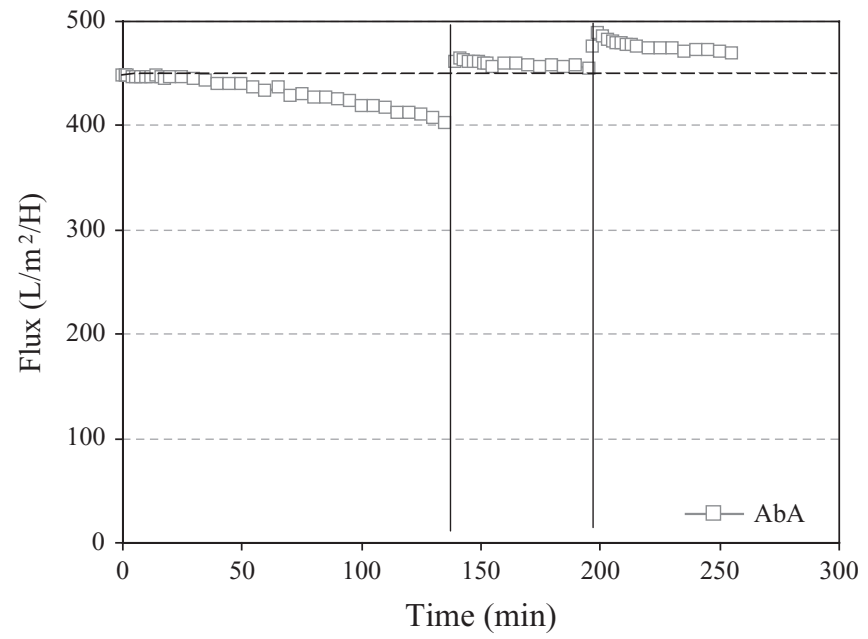

(a) AbA with YM100 membrane

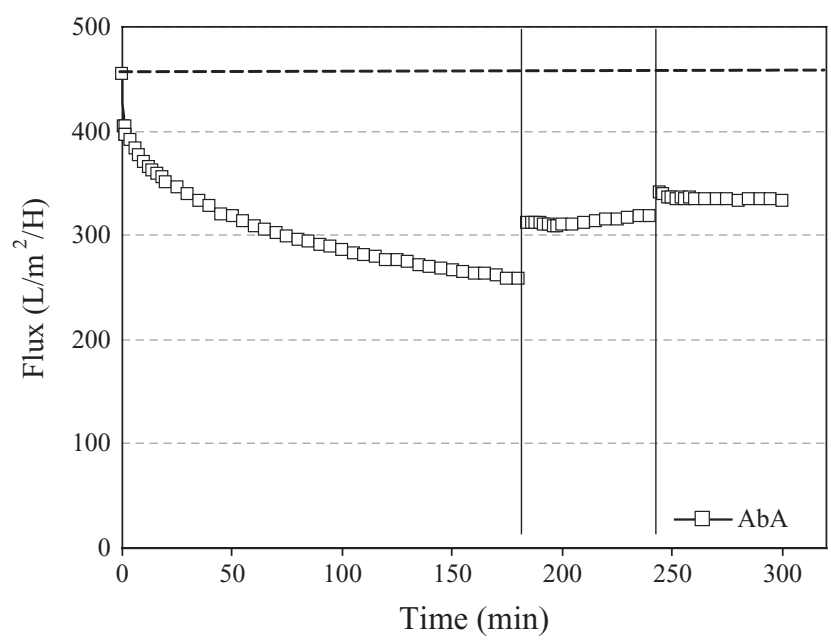

(b) AbA with PES membrane

Fig. 6. Flux decline caused by abietic acid (AbA) filtration (0-180 min), MQ water filtration with fouled membrane (180-245 min) and MQ water filtration after normal backwash (245-300 min) using the (a) YM100 and (b) PES membranes. 


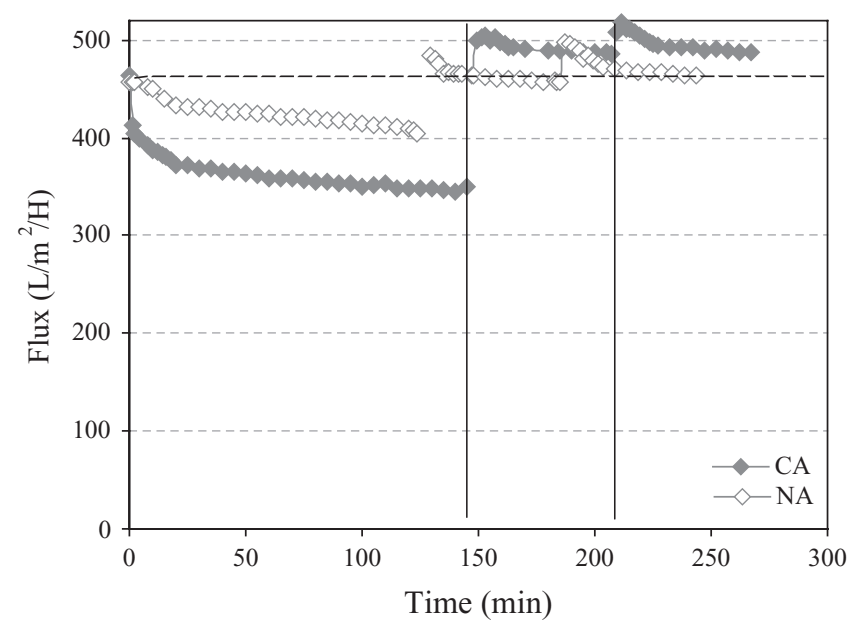

(a) CA and NA with YM100 membrane

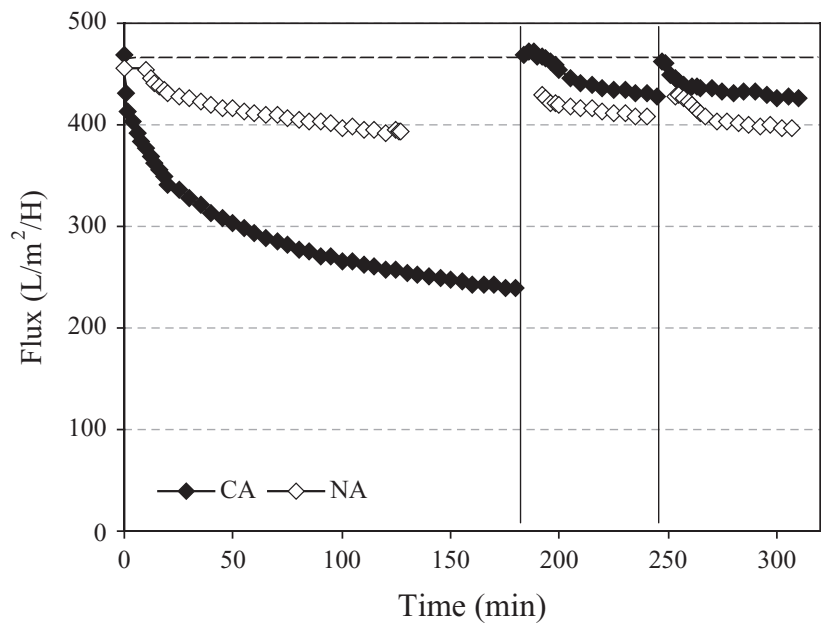

(b) CA and NA with PES membrane

Fig. 7. Flux decline caused by colominic acid (CA) and N-acetylneuraminic acid (NA) filtration (0-180 min), MQ water filtration with fouled membrane (180-245 $\mathrm{min}$ ) and MQ water filtration after normal backwash (245-300 min) using the (a) YM100 and (b) PES membranes.

membrane than it was with the YM100 membrane when fouled with $\mathrm{CA}$; while similar flux decline was recorded for NA in both membranes. The YM100 membrane (Fig. 7a) fouled with CA and NA provided flux reduction of 100 and $50 \mathrm{~L} / \mathrm{m}^{2} / \mathrm{h}$, respectively. Similar flux decline was observed for the PES membrane fouled with NA while a higher flux drop of $240 \mathrm{~L} / \mathrm{m}^{2} / \mathrm{h}$ was recorded for the PES membrane fouled with CA (Fig. 7b). CA has a higher molecular weight than NA resulting in a membrane surface fouling that caused higher flux decline. After normal backwash, flux was reversible for both PES and YM100 membranes (Fig. 7a and b).

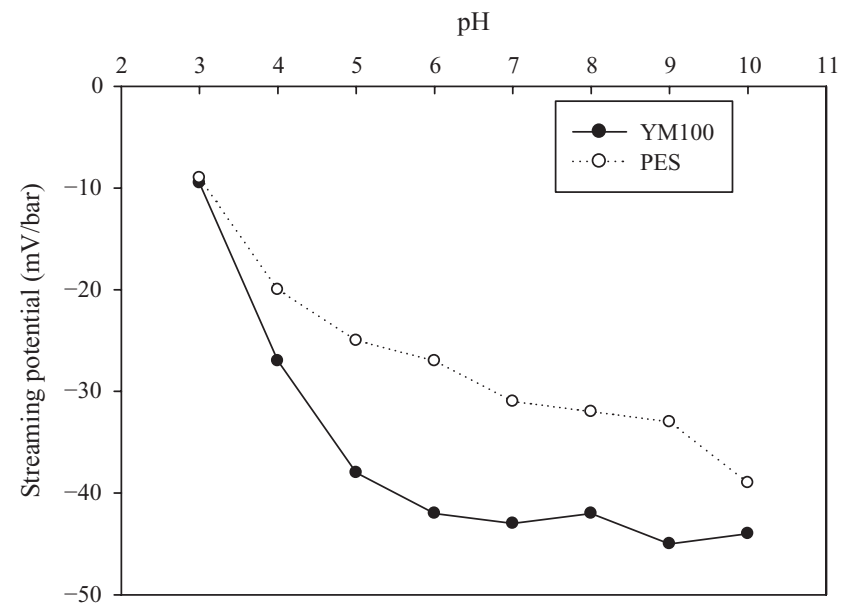

Fig. 8. SP $(\Delta \Phi / \Delta P)$ coefficients of clean PES and YM100 membranes, as measured with $\mathrm{MQ}$ water at different $\mathrm{pH}$ values.

\subsection{SP - clean and fouled membranes}

The SP coefficients of the clean membranes were measured at different $\mathrm{pH}$ values adjusted with either $0.1 \mathrm{~N} \mathrm{NaOH}$ or $0.1 \mathrm{~N} \mathrm{HCl}$ (Fig. 8). An iso-electric point (IEP) was approximately between $\mathrm{pH} 2$ and 3.

The SP coefficient of the YM100 membrane had higher negative values than the PES membrane. The SP flow difference was measured through the pores of the membrane, not across the membrane surface. Thus, the charge of both the YM100 and PES membrane pores had very low negative values.

SP measurements for the fouled membranes were conducted for comparison to those of the corresponding clean membranes. The SP results shown in Fig. 9 were measured at various $\mathrm{pH}$ values ranging $4-8$. For YM100 and PES membranes, the increase of $\mathrm{pH}$ caused decrease of the SP for all the MOCs tested, which indicates that adsorption of negatively charged compounds in the membranes pores occurred (Fig. 9). Similar findings were reported by Pontié et al. [24].

Adsorbed MOCs changed the SP value of both the YM100 and PES membranes (Fig. 9). The relatively smaller decrease in the SP coefficient values for the PES membrane than for the YM100 membrane were observed, but the original SP coefficient values for the PES membrane was less than those of the YM100 membrane. Thus, membrane initial charge seems to greatly affect the SP coefficients.

The plots of SP versus pressure (from 0 to 1.2 bars) at $\mathrm{pH} 7.2$ exhibit negative slope, indicating a negatively charged surface (Fig. 10). For the YM100 membrane, AA (polymer), AA (dimmer), and CA gave slightly 
Table 3

DOC values (mg/L) of the feed, permeate and retentate solutions using different MOCs (alginic acid (AA), abietic acid (AbA), $\mathrm{N}$-acetylneuraminic acid (NA), and colominic acid (CA))

\begin{tabular}{|c|c|c|c|c|c|c|}
\hline \multirow[t]{2}{*}{ MOCs } & \multicolumn{3}{|c|}{ YM100 } & \multicolumn{3}{|l|}{ PES } \\
\hline & Feed & Permeate & Retentate & Feed & Permeate & Retentate \\
\hline AA (polymer) & 5.2 & 0.7 & 38.8 & 5.4 & 0.5 & - \\
\hline AA (dimmer) & 5.1 & 0.4 & 30.0 & 5.0 & 0.5 & 27.9 \\
\hline $\mathrm{AbA}$ & 4.6 & 4.5 & 6.7 & 5.1 & 4.8 & - \\
\hline CA & 4.6 & 4.3 & 18.5 & 4.1 & 0.8 & 38.3 \\
\hline NA & 4.7 & 4.7 & 5.3 & 3.6 & 3.6 & 4.3 \\
\hline
\end{tabular}

higher negative SP values than the clean membrane. $\mathrm{AbA}$ and NA gave slightly lower SP values compared to the clean membrane with $\mathrm{AbA}$ SP $(-40 \mathrm{mV} / \mathrm{bar})$

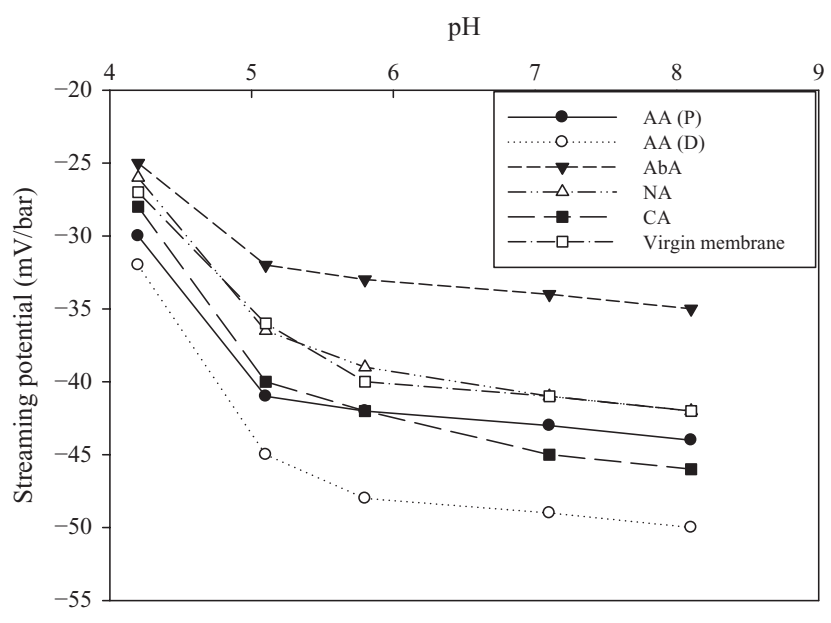

(a) YM100 membrane

$\mathrm{pH}$

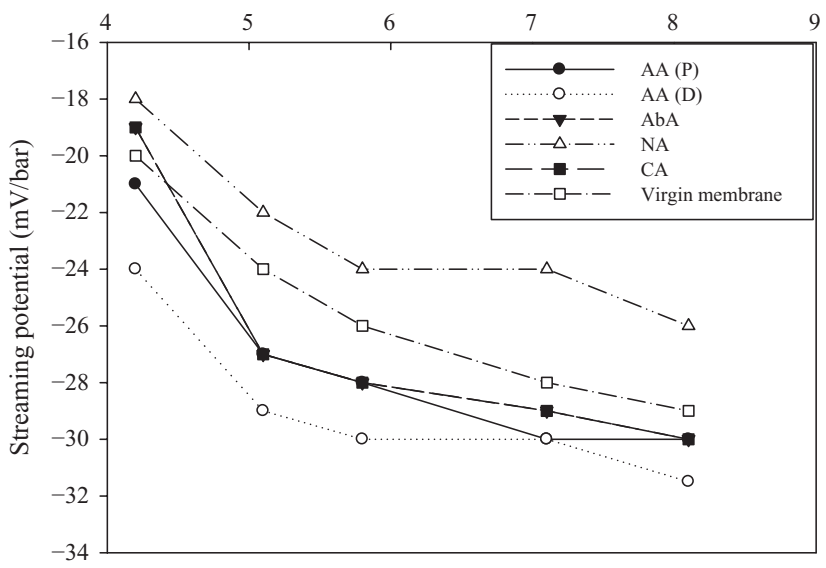

(b) PES membrane

Fig. 9. SP $(\Delta \Phi / \Delta P)$ at varying $\mathrm{pH}$ of MOCs (alginic acid (AA), abietic acid (AbA), $N$-acetylneuraminic acid (NA), and colominic acid (CA)) fouled membranes (YM100 (a) and PES (b)) and membranes washed with MQ water. being the lowest negative potential (Fig. 10a). This indicates that fouling of AA (polymer), AA (dimmer), and CA increased slightly the membrane charge through adsorption, while the opposite occurred with AbA and NA fouling. When correlating SP values with the results of flux decline for the YM100 membrane, we

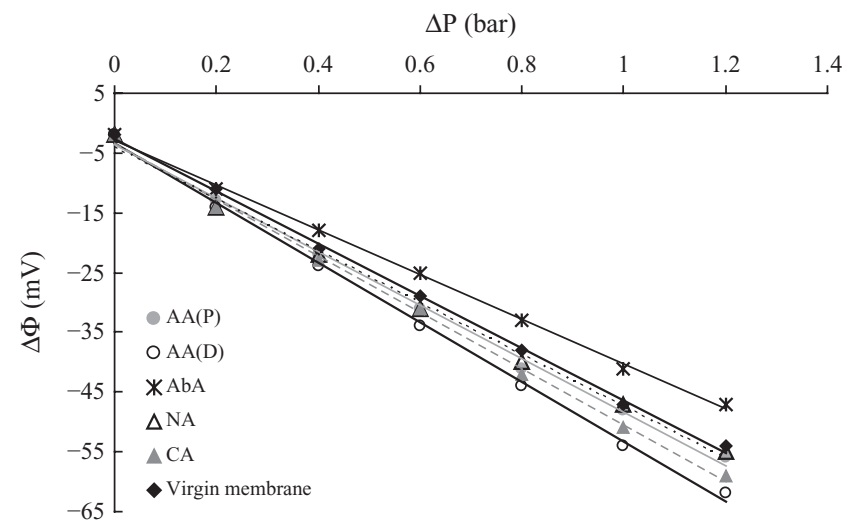

(a) YM100 membrane

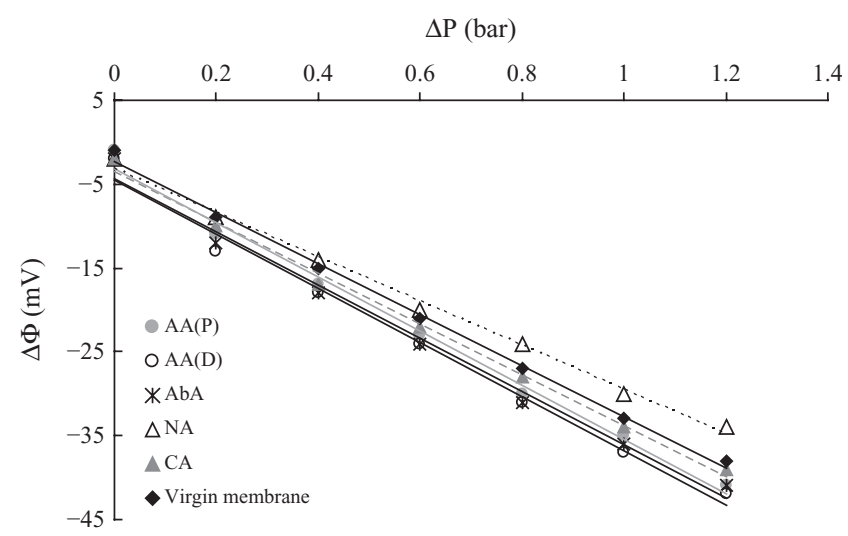

(b) PES membrane

Fig. 10. Potential difference with increasing pressure at pH 7.2 of MOCs (alginic acid (AA), abietic acid (AbA), $\mathrm{N}$-acetylneuraminic acid (NA), and colominic acid (CA)) fouled membranes (YM100 (a) and PES (b)) and membranes washed with MQ water. 
observed that AA (polymer), AA (dimmer), and CA showed high flux decline caused by fouling (higher negative SP), while flux decline caused by $\mathrm{AbA}$, and NA fouling was very low. This can lead us to conclude that AA (polymer), AA (dimmer), and CA are more detrimental foulant for YM100 membrane than are $\mathrm{AbA}$ and NA.

Regarding the PES membrane, AA (polymer), AA (dimmer), $\mathrm{AbA}$, and $\mathrm{CA}$ gave slightly higher negative $S P$ values than MQ with the clean membrane, although NA showed slightly lower SP values compared to MQ with the clean membrane (Fig. 10b). The results of flux decline are correlated to SP values for the PES membrane, we observed that AA (polymer), AA (dimmer), AbA, and CA induced high flux decline caused by membrane fouling (higher negative SP), while flux decline caused by NA fouling was very low. Consequently, $\mathrm{AA}$ (polymer), $\mathrm{AA}$ (dimmer), $\mathrm{AbA}$, and $\mathrm{CA}$ are more serious foulant for the PES membrane than is NA.

\section{Discussion}

The fouling of the two membranes was found to be the highest with AAs, as compared to the other MOCs. The AAs were deposited and accumulated on the membrane surface where their concentration gradually increased. The AbA and NA containing lower molecular weights, with the exception of AA (dimmer), exhibited relatively low flux decline with the YM100 membrane (Figs. 5-7). However, with the PES membrane, $\mathrm{AbA}$ provided relatively high flux declines. Most of the solutes could pass through the membrane pores, as identified by the DOC measurement results (Table 3). During the passing, the solutes appeared to be adsorbed on the pore walls and on the membrane surface. Although most of the $\mathrm{AbA}$ was able to pass through the membrane pores, some of $\mathrm{AbA}$ were adsorbed onto the pore walls of the PES membrane due to hydrophobic interactions (the extent of hydrophobicity of $\mathrm{AbA}$ is very high as $\log K_{\mathrm{ow}}$ of $\mathrm{AbA}$ is 4.4). This was confirmed by the flux recovery experiment results with $M Q$, where flux did not recover to the corresponding initial flux. The fouling due to $\mathrm{AbA}$ can be defined as irreversible internal fouling. However, this phenomenon was not observed with the YM100 membrane, which could also confirm the hydrophobic interaction supposition as the YM100 membrane is relatively hydrophilic, compared to the PES membrane. The intrinsic membrane resistance of the YM100 membrane was higher than that of the PES membrane, but with less fouling, which may be the result of the morphological differences in the membranes.
Membrane polarity and roughness were found to be linked to fouling tendency over long term experiments [16]. The geometrical areas of membranes (YM100 and PES) used in our study are the same, while the areas of contact between the solute and the solvent were higher for the PES membrane due to its roughness compared to the relatively smooth YM100 membrane (Fig. 2). This roughness was presumably behind the higher fouling propensity of PES membrane and which confirms with Weis et al. findings [16].

CA appeared to be associated with external fouling due to the concentration polarization of the solutes retained on the membrane surface as the low DOC values of permeate samples and effective flux recovery with MQ were observed. From the results of the lower flux decline associated with NA than with CA, membrane fouling, and subsequent flux decline were revealed to be affected by the molecular weight difference, regardless of the similar chemical compositions.

\section{Conclusions and recommendations}

Fouling mechanisms of MOCs on two UF membranes (YM100 and PES) were investigated and the following conclusions were obtained:

- The fouling of PES membrane by MOCs was higher than that of the YM100 membrane, and PES suffered irreversible flux decline (by solute adsorption on the pore walls of membrane).

- AA (polymer), AA (dimmer), and CA are more detrimental foulant for YM100 membrane than are AbA, and NA; while AA (polymer), AA (dimmer), AbA, and $\mathrm{CA}$ are more serious foulant for the PES membrane than is NA.

- Severe flux decline (approximately double the flux decline caused by AbA, CA, and NA for YM100 membrane) was observed with both AAs compared to the other MOCs, but the flux recovery was achieved after the filtration of MQ.

- AA (polymer), AA (dimmer), and CA caused external fouling (concentration polarization and cake or gel layer formation), which was characterized by particle deposition on the membrane surface. This formation of fouling caused by polysaccharides components was solved by periodic membrane cleaning with MQ.

- The use of a cross flow membrane system decreased the fouling caused by MOCs to a greater extent than the dead-end type filtration. If a reasonably high cross flow velocity is applied as an operating condition, the fouling due to these compounds can be reduced. 
- The SP measurements showed slight difference between the virgin membrane and the marginally fouled membranes by MOCs. However, for a highly fouled membrane, the SP value provided better understanding of the electro-kinetics interactions between membranes and solutes as well as fouling severity.

Based on these findings, many other investigations could be made to assess the relationship between different organic and inorganic compounds and fouling. Additionally, the use of chemical membrane cleaning using various cleaning agents could also be performed to study their effect on flux restoration after membrane fouling due to MOC.

\section{Acknowledgements}

This research was supported mainly by a grant from the National Research Laboratory Program by the Korea Science and Engineering Foundation (NOM Ecology Lab: R0A-2007-000-20055-0), and in part by Université de Poitiers, Lab. Chimie de I'Eau et de I'Environnement, UMR CNRS6008. We also appreciate Dr. Maxime pontié (SP apparatus and FESEM) for this study.

\section{Nomenclature}

$J_{\mathrm{v}} \quad$ volume flux of the permeate water $(\mathrm{m} / \mathrm{s})$

$\Delta \mathrm{P}$ transmembrane pressure (bar)

$\mathrm{R}_{\mathrm{m}} \quad$ intrinsic membrane resistance $\left(\mathrm{m}^{-1}\right)$

$T$ ambient temperature $\left(^{\circ}\right)$

$\eta_{\mathrm{T}} \quad$ feed water viscosity $\left(\mathrm{Ns} / \mathrm{m}^{2}\right)$

$\Delta \phi \quad$ electrical potential difference $(\mathrm{mV})$

$\phi_{\mathrm{f}} \quad$ electrical potential of feed $(\mathrm{mV})$

$\phi_{\mathrm{p}} \quad$ electrical potential of permeate $(\mathrm{mV})$

$\nu \quad$ streaming potential coefficient $(\mathrm{mV} / \mathrm{bar})$

\section{References}

[1] J. Cho, G. Amy, J. Pellegrino and Y. Yoon, Desalination, 118 (1998) 101-108.

[2] A. Seidel and M. Elimelech, J. Membr. Sci., 203 (2002) 245-255.

[3] T. Carroll, N.A. Booker and J. Meier-Haack, J. Membr. Sci., 203 (2002) 3-13.

[4] M. Zhang, C. Li, M.M. Benjamin and Y. Chang, Environ. Sci. Technol., 37 (2003) 1663-1669.

[5] E. Aoustin, A.I. Schawfer, A.G. Fane and T.D.Waite, Sep. Purif. Technol. 22-23 (2001) 63-78.

[6] K.L. Jones and C.R. O'Melia, J. Membr. Sci., 165 (2000) 31-46.

[7] D. Jermann, W. Pronk, S. Meylan and M. Boller, Water Res., 41 (2007) 1713-1722.

[8] K. Kimura, Y. Hane, Y. Watanabe, G. Amy and N. Ohkuma, Water Res., 38 (2004) 3431-3441.

[9] M.D. Kennedy, H.K. Chun, V.A. Quintanilla Yangali, B.G.J. Heijman and J.C. Schippers, Desalination, 178 (2005) 73-83.

[10] A. Ikeda, A. Takemura and H. Ono, Carbohydr. Polym., 42 (2000) 421-425.

[11] J. Villalaín, Biochim. Biophys. Acta, 1328 (1997) 281-289.

[12] M. Masuda, Y. Kawase and M. Kawase, J. Biosci. Bioeng., 89 (2000) 119-125.

[13] Y. Du, A. Taga, S. Suzuki, W. Liu and S. Honda, J. Chromatogr. A, 962 (2002) 221-231.

[14] A.R. Costa, M.N. De Pinho and M. Elimelech, J. Membr. Sci., 281 (2006) 716-725.

[15] H. Zhu and M. Nyström, Colloid Surf. A, 138 (1998) 309-321.

[16] A. Weis, M.R. Bird, M. Nyström and C. Wright, Desalination, 175 (2005) 73-85.

[17] D.I.C. Wang, A.J. Sinskey and T. Sonoyama, Biotechnol. Bioeng., 11(1969) 987-1003.

[18] K. Larson, Desalination, 35 (1980) 105-114.

[19] K.J. Kim, A.G. Fane, M. Nystrom, A. Pihlajamaki, W.R. Bowen and H. Mukhtar, J. Membr. Sci., 116 (1996) 149-159.

[20] M.C. Wilbert, S. Delagah and J. Pellegrino, J. Membr. Sci., 161 (1999) 247-261.

[21] M. Pontié, J. Membr. Sci., 154 (1999) 213-220.

[22] M. Pontié, X. Chasseray, D. Lemordant and J.M. Lainé, J. Membr. Sci., 129 (1997) 125-133.

[23] D. Möckel, E. Staude, M. Dal-Cin, K. Darcovich and M. Guiver, J. Membr. Sci., 145 (1998) 211-222.

[24] M. Pontié, L. Durand-Bourlier, D. Lemordant and J.M. Lainé, Sep. Purif. Technol., 14 (1998) 1-11.

[25] A.E. Childress and M. Elimelech, J. Membr. Sci., 119 (1996) 253-268.

[26] N.D. Lawrence, J.M. Perera, M. Iyer, M.W. Hickey and G.W. Stevens, Sep. Purif. Technol., 48 (2006) 106-112. 